\title{
Left Ventricular Assist Device
}

National Cancer Institute

\section{Source}

National Cancer Institute. Left Ventricular Assist Device. NCI Thesaurus. Code C80473.

A mechanical pump which also includes a control system and an energy supply. It

receives blood from the left ventricle and delivers it to the aorta, thus helping the heart to pump sufficient blood to the body. 